\title{
Diagnosis of inflammatory demyelination in biopsy specimens: a practical approach
}

\author{
Tanja Kuhlmann $\cdot$ Hans Lassmann $\cdot$ Wolfgang Brück
}

Received: 17 September 2007 / Revised: 8 November 2007 / Accepted: 8 November 2007 / Published online: 4 January 2008

(C) The Author(s) 2008

\begin{abstract}
Multiple sclerosis is the most frequent demyelinating disease in adults. It is characterized by demyelination, inflammation, gliosis and a variable loss of axons. Clinically and histologically, it shares features with other demyelinating and/or inflammatory CNS diseases. Diagnosis of an inflammatory demyelinating disease can be challenging, especially in small biopsy specimens. Here, we summarize the histological hallmarks and most important neuropathological differential diagnoses of early MS, and provide practical guidelines for the diagnosis of inflammatory demyelinating diseases.
\end{abstract}

Keywords Multiple sclerosis · Demyelination ·

Inflammation

\section{Introduction}

Multiple sclerosis (MS) is the most frequent demyelinating disease in humans. Worldwide, it affects approximately 1 million adults [7]. The annual costs are estimated to amount up to $€ 72,000$ per year per patient depending on the severity of the disease.

T. Kuhlmann $(\bowtie) \cdot$ W. Brück

Department of Neuropathology,

University Medical Centre Göttingen,

Robert-Koch-Str. 40, 37075 Göttingen, Germany

e-mail: tanjakuhlmann@gmx.de

H. Lassmann

Center for Brain Research,

Medical University Vienna, Vienna, Austria

W. Brück

Institute for Multiple Sclerosis Research,

Gemeinnützige Hertie-Stiftung and University Medical

Centre Göttingen, Göttingen, Germany
Due to the typical clinical symptoms, changes in CSF and MRI findings in MS patients, biopsies are only rarely required to establish the diagnosis. However, biopsies are occasionally performed to exclude other treatable diseases such as tumours, vasculitis or viral infections. The histological characteristics of chronic MS lesions are well known to neuropathologists, however diagnosing an inflammatory demyelinating process in biopsy specimens may be challenging since the specimens are frequently small and often represent only parts of a bigger lesion. Furthermore, the histopathological hallmarks of acute MS differ fundamentally from the well-known characteristics of chronic demyelinated plaques observed in autopsies. Here, we describe the histopathological characteristics and most important differential diagnoses of early MS lesions. Histopathologically, the differential diagnoses of multiple sclerosis includes other demyelinating diseases (Acute disseminated encephalomyelitis (ADEM), HURST, vanishing white matter disease, Alexander's disease, X-linked adrenoleukodystrophy (ALD) and central pontine myelinolysis (CPM)), inflammatory diseases (vasculitis, viral infections), sentinel lesions preceding lymphomas, tumours (lymphomas, astrocytomas, oligodendrogliomas) and infarcts. In the last 3 years, we received about 100 biopsies from patients with MS. About $40 \%$ of the MS lesions were actively demyelinating lesions in which a further classification in different histological patterns according to Lucchinetti, Lassmann and Brück [53] was possible. In our experience the most frequent differential diagnoses include vasculitis and encephalitis. Other disease entities, such as Alexander's disease, vanishing white matter disease and PML are rare diseases and are even more rarely biopsied. However, at our institution, we have seen single examples of Alexander's disease $(n=2)$, vanishing white matter disease $(n=1)$, few examples of PML $(n=2)$, ALD 
$(n=1)$, measles encephalitis $(n=2)$, Rassmussen encephalitis $(n=1)$, sentinel lesions $(n=4)$ or ADEM/HURST $(n=5)$ during the last 5 years. CPM and MarchiafaviBignami are relatively rare diseases that most likely will not be biopsied. We included them in our list of differential diagnoses since they belong to the spectrum of demyelinating diseases and can be found occasionally in autopsies.

In this review, we discuss the differential diagnoses and suggest practical guidelines for diagnosing inflammatory demyelination in biopsy specimens.

\section{Demyelinating diseases}

\section{Multiple sclerosis}

The key features of early MS lesions are demyelination, extensive macrophage invasion, perivascular and parenchymal T cell infiltrates as well as relative axonal preservation. Long-lasting chronic MS lesions (e.g. seen at autopsy) are characterized by a relatively uniform appearance of extensive primary demyelination (Fig. 1a) with variable axonal loss, gliosis and minor infiltration by lymphocytes and macrophages/microglia (Fig. 1b). Early MS lesions show a profound inflammatory reaction consisting of $\mathrm{T}$ cells, a variable but low number of $\mathrm{B}$ cells and massive infiltration by foamy macrophages at the sites of demyelination (Fig. 1c, d, e, f). A prominent reactive astrocytosis with formation of so-called gemistocytes is another key feature of early MS lesions. In addition, single dividing astrocytes (so-called Creutzfeldt-Peters cells) can be observed. Ongoing remyelinating areas as well as areas with active demyelination can often be seen next to each other [16]. In MS lesions with areas of ongoing myelin destruction, three different patterns based on the myelin protein loss, extent of oligodendrocyte preservation and composition of the inflammatory infiltrates can be distinguished [53]. Patterns I (Fig. 1c, d, e, f) and II share most of the histological characteristics. Both patterns are characterized by a sharp border to the normal appearing white matter and an even loss of all myelin proteins (MBP, CNP, PLP, MAG, MOG). Areas of active demyelination (defined by the presence of myelin degradation products, such as MOG or CNP within the cytoplasm of macrophages [18]; insert in Fig. 1d) are infiltrated by $\mathrm{T}$ lymphocytes, some plasma cells and numerous foamy macrophages. Macrophages represent the dominant cell population in MS lesions and easily outnumber T lymphocytes by a factor of 10 (Fig. 1d, e, f). The percentage of CD8-positive T cells varies by around $50-80 \%$ of the $\mathrm{T}$ cell population. In contrast to pattern I lesions, pattern II lesions show deposition of activated complement (C9neo) on degenerating myelin sheaths and in macrophages. Pattern III MS lesions are characterized by an ill- defined lesion border (Fig. 1g) and a preferential loss of MAG, while other myelin proteins such as MBP, PLP or MOG are still present or even appear to be overexpressed in the lesion. Pattern III lesions demonstrate a marked oligodendroglial loss; in areas of active myelin degradation, and at the plaque border, oligodendrocytes with apoptotic morphology can be observed (Fig. 1h). The inflammatory infiltrates consist of $T$ cells, activated microglia/macrophages and some plasma cells; complement deposits are not observed in pattern III lesions. A fourth pattern characterized by demyelination due to dying oligodendrocytes in the normal appearing white matter has been described in single autopsy specimens of MS patients with a primary-progressive disease course [53]. Since this pattern has been observed only post mortem in single patients, we do not describe it in more detail here.

A special variant of inflammatory demyelinating lesions is seen in patients with Devic's type of neuromyelitis optica. NMO lesions (Fig. 1i, j) [54], which do not necessarily have to be confined to the spinal cord and optic nerves, display necrotic changes in addition to primary demyelination. These lesions are infiltrated by a significant number of eosinophils and neutrophils, in addition to $\mathrm{T}$ cells and macrophages, and show prominent vascular fibrosis and hyalinization. Typical features are a profound loss of astrocytes (Fig. 1i) and in particular of the astrocytic protein aquaporin-4 [80]. Complement reactivity, which is found predominantly on astrocytes of the glia limitans, is seen in a rim or rosette-like pattern around vessels [54] (Fig. 1j). In the serum of NMO patients, a specific antibody reaction has recently been identified, which is directed against the astrocytic water channel aquaporin-4 [50], and which may help towards a final diagnosis in such patients.

Acute disseminated encephalomyelitis and acute haemorrhagic necrotizing leukoencephalitis

Acute disseminated encephalomyelitis (ADEM) and acute haemorrhagic necrotizing leukoencephalitis (AHL or Hurst syndrome) are monophasic diseases, which most commonly affect children or young adults. The patients present with multifocal neurological symptoms often associated with a disturbed consciousness [35, 59, 78]. Recurrent disease courses have been suggested in single patients, making a clinical differentiation between ADEM and MS difficult [22, 76]. The clinical outcome of ADEM is typically favourable in contrast to its fulminant variant, Hurst syndrome. The pathophysiology of these diseases is unknown. An autoimmune response to a CNS antigen triggered by infection or vaccination has been discussed as the underlying disease mechanism, since ADEM and Hurst syndrome are often (but not always) associated with preceding infections of the upper respiratory tract or vaccinations $[41,71]$. 
Fig. 1 Chronic and early MS lesions. Chronic MS lesions have a sharp border with the surrounding normal appearing white matter [NAWM; LFBPAS staining; (a)]. Frequently, the demyelinated lesion centre is hypocellular while the lesion border and the normal appearing white matter show an increased number of macrophages and/or microglia (immunohistochemistry for the macrophage/ microglial marker KiM1P (b) and insert). Early MS lesions with pattern I are characterized by a sharp border with the NAWM [LFB-PAS staining; (c)]. The inflammatory infiltrates are dominated by foamy macrophages [immunohistochemistry for $\operatorname{KiM} 1 \mathrm{P}(\mathbf{d})]$, which may contain myelin degradation products in their cytoplasm (immunohistochemistry for the myelin protein MBP (insert in $d)$ ). T cells are diffusely distributed within the parenchyma of the lesion (e), but may also be found perivascularly in NAWM [immunohistochemistry for CD3; (f)]. Pattern III lesions show an ill-defined lesion border [LFB-PAS staining; (g)]. In areas of active demyelination and NAWM, numerous dying oligodendrocytes (arrows) with condensed nuclei are observed [immunohistochemistry for CNP; (h)]. The insert in $h$ shows a higher magnification of a CNPpositive oligodendrocyte with a condensed nucleus. In NMO, a loss of astrocytes and glial fibres [immunohistochemistry for GFAP; (i)] as well as a perivascular deposition of complement is observed [immunohistochemistry for C9neo; (j)]
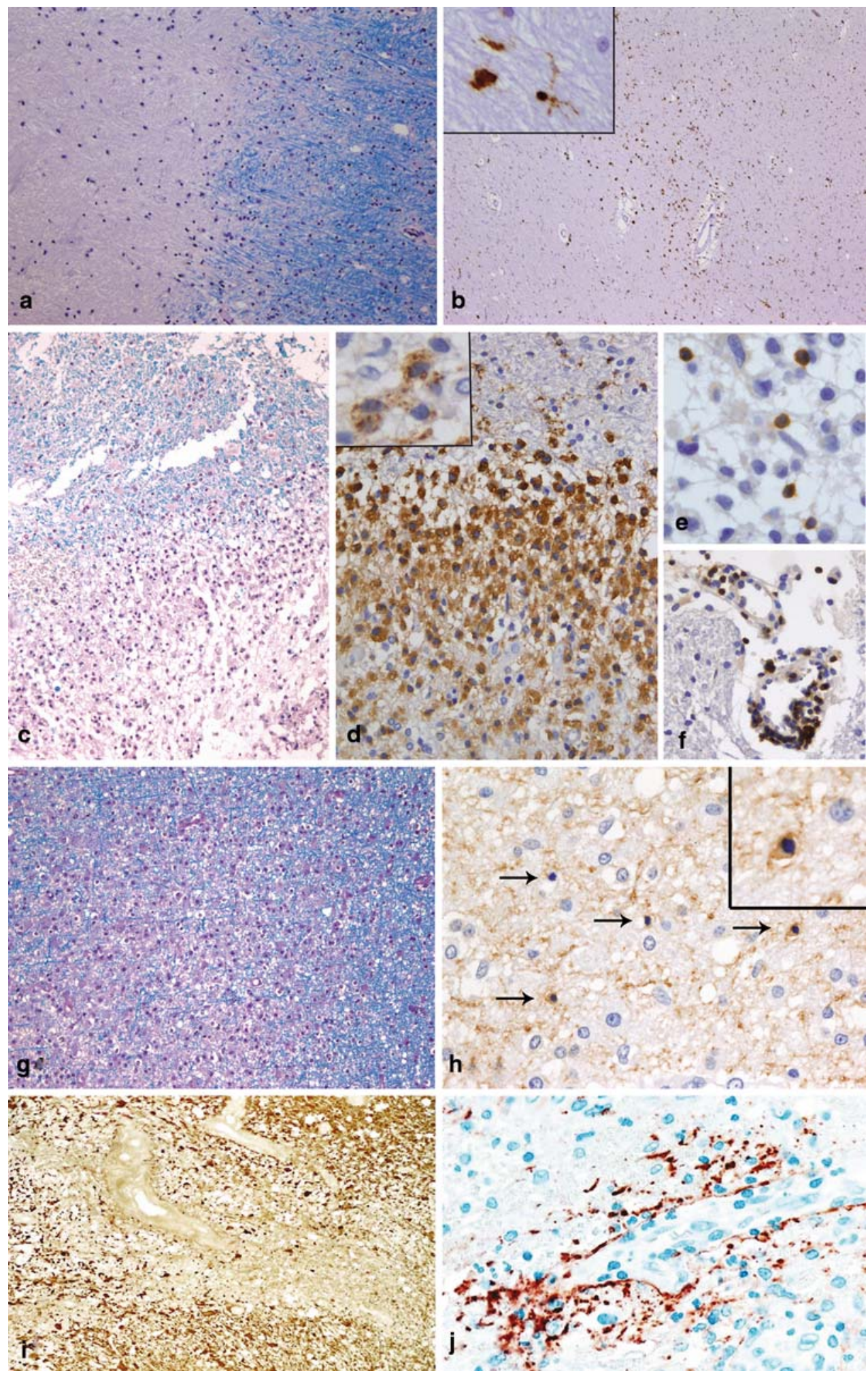

Histologically, ADEM is characterized by small perivascular demyelinating lesions (Fig. 2a), which may be confluent. The perivascular demyelinating "rim" is infiltrated by numerous foamy macrophages and a few lymphocytes (CD3- and CD8-positive T cells, B cells and plasma cells)
(Fig. 2b). In general, demyelination is-in contrast to MS lesions-limited to perivascular areas with inflammatory infiltrates. Thus, in brain biopsies profound inflammation in the white matter, which is associated with perivascular demyelination only, is suggestive of ADEM. Having said 
Fig. 2 Different demyelinating diseases. ADEM is characterized by very limited perivascular demyelination [LFB-PAS; (a)] and perivascular infiltrates that consist mostly of foamy macrophages [immunohistochemistry for KiM1P; (b)]. In vanishing white matter, a diffuse loss of myelin is observed [LFB-PAS; (c)]. The number of oligodendrocytes in affected white matter areas is markedly reduced [immunohistochemistry for $\mathrm{CN}$ Pase (d)]. In contrast to early MS lesions, the demyelinated lesions are infiltrated by relatively few macrophages [immunohistochemistry for KiM1P; (e)]. In $\mathrm{X}$-linked adrenoleukodystrophy, numerous bizarre astrocytes can be found within the lesions (arrows in $\mathbf{f}$ ) as well as lymphocytic perivascular infiltrates (arrowhead in $f$; haematoxylin and eosin staining). The lesion areas are completely demyelinated (g) and in macrophages needle-like inclusions may be found (insert in $g$ ). In Alexander's disease large CNS areas with an almost complete loss of myelin are found [immunohistochemistry for MBP; (h)]. The histopathological characteristic of Alexander's disease is numerous GFAP-positive Rosenthal fibres [immunohistochemistry for GFAP; (i)]
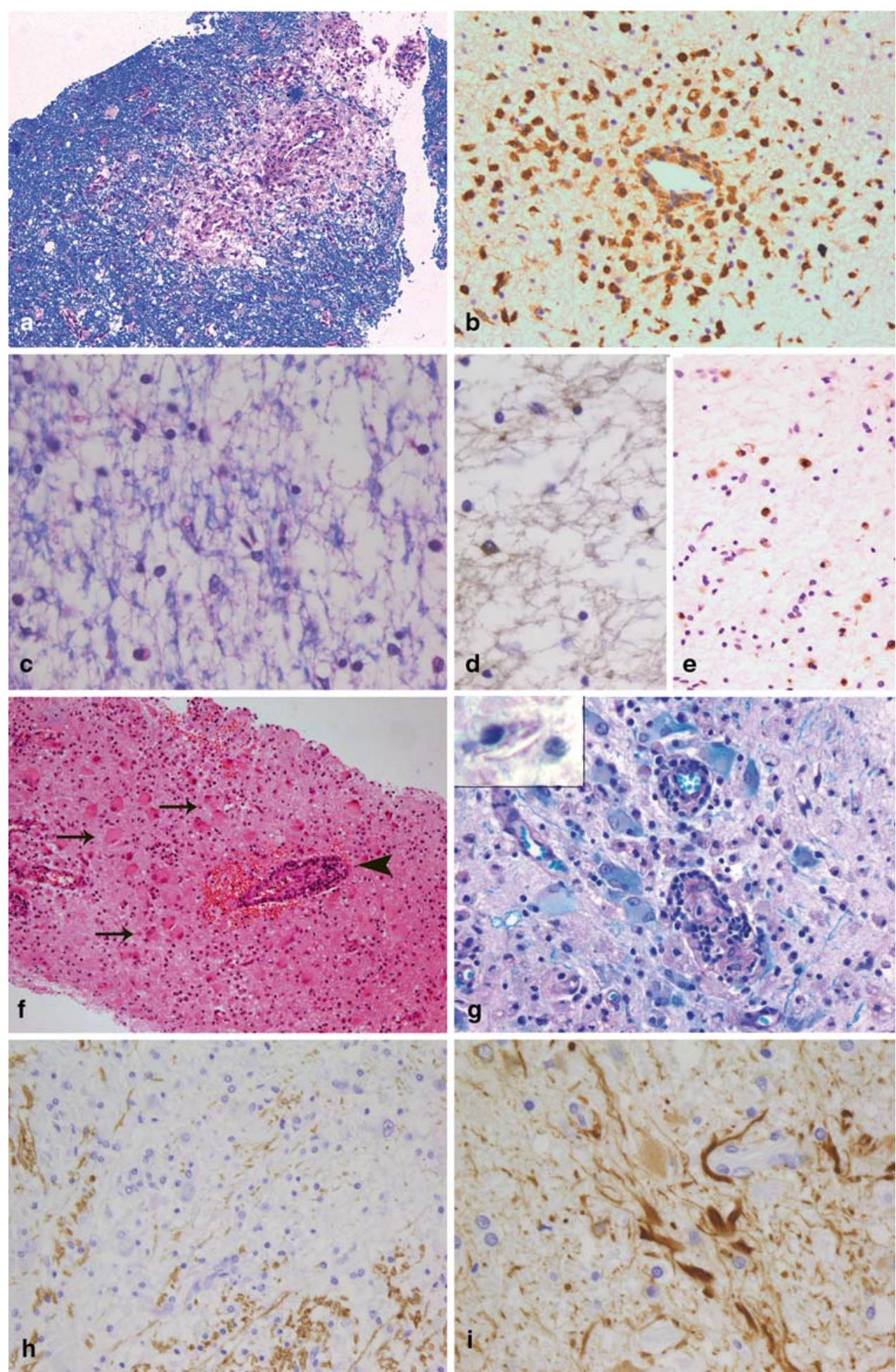

this, however, it is nevertheless true that essentially similar tissue alterations can be seen in the vicinity of active MS lesions. It is therefore frequently not possible to definitely distinguish between ADEM and MS, in particular when only small biopsy specimens are available.

Hurst syndrome displays circular haemorrhages and fibrin deposits around smaller often necrotic vessels together with infiltrates consisting of neutrophils, lymphocytes and macrophages. Among the inflammatory cells, neutrophils are the dominant cell population. Similar to ADEM, the loss of myelin is limited to the area of inflammation. Frequently, the axon cylinders are severely affected resulting in necrotic foci rather than real demyelination $[1$, 34]. 
Central pontine myelinolysis

In 1959, Adams described for the first time a disease characterized by demyelinating symmetrically located central pontine lesions and therefore named it central pontine myelinolysis [2]. Subsequent studies revealed that such demyelinating lesions are not confined to the pons, but can be found in other regions of the brain that show a strong admixture of grey and white matter such as cerebellum or the extreme and external capsule [31, 64]. Central pontine myelinolysis (CPM) is a rare disease associated with conditions such as alcoholism, chronic malnutrition, cirrhotic liver disease and transplantation. CPM has been related to a rapid rise of serum sodium from a hyponatremic baseline and similar demyelinating lesions have been found experimentally such as electrolyte-induced myelinolysis in rats [44, 45, 62].

Histopathologically, these lesions are characterized by extensive, sharply demarcated demyelinating lesions. Oligodendrocytes are completely eliminated. The extent of axonal damage varies between patients [30]; older lesions may display cystic (necrotic) cavitations in the centre of the demyelinating lesion [60]. Neurons are well preserved. Within the lesions, numerous macrophages are observed. The number of macrophages as well as the presence of LFB-positive myelin degradation products within the cytoplasm of macrophages depends on the age of the lesion. In contrast to MS lesions, lymphocytic infiltrates are rare. In general, the diagnosis of CPM can be easily made due to the typical distribution of the lesions. Even in rare instances when extrapontine lesions are not accompanied by pontine lesions [31, 64], the lack of lymphocytic infiltrates in CPM lesions makes confusion with early MS unlikely.

A second demyelinating condition observed almost exclusively in alcoholics is Marchiafava-Bignami (MFB) disease. In MFB disease, lesions are mostly located in the corpus callosum, but they may also be found in the optic chiasm, anterior commissure and cortex [38]. The histopathological characteristics are very similar to the changes observed in CPM, indicating that these two conditions may share some pathogenic mechanisms. However, MFB and CPM are rarely observed in the same patient [29].

\section{Vanishing white matter disease}

Vanishing white matter (VWM) disease, also called myelinopathia centralis diffusa or childhood ataxia with diffuse central hypomyelination, has only recently been recognized as a disease entity caused by mutations in the EIF2B1 gene family $[49,86]$. In the majority of cases, the disease begins neonatally or in early childhood after infections with fever or mild head injuries with an episodic or progressive neurological deterioration. The neurological symptoms include cerebellar ataxia, spasticity, optic atrophy and epilepsy. In addition to disease onset in childhood, adult cases are also described [12, 27, 73]. MRI reveals diffuse signal abnormalities and cystic changes in the cerebral white matter [73, 84, 85]. Due to its neurological characteristics, early disease onset and extensive MRI abnormalities, the disease would only rarely be considered as a differential diagnosis to MS in children. However, in adults the diagnosis of the disease may be difficult. Histopathologically, the disease is characterized by a widespread, diffuse loss of myelin and oligodendrocytes (Fig. 2c, d), accompanied by a significant reduction in axons, characteristics also found in MS lesions [17, 74, 88, 91]. In contrast to early MS lesions, only a moderate infiltration with macrophages/microglia is observed and $\mathrm{T}$ and $\mathrm{B}$ cells are absent (Fig. 2e) [15]. Although only moderate numbers of macrophages/microglial cells are seen in VWM disease, single macrophages containing myelin degradation products, such as MAG, CNP, etc. within their cytoplasm may be present in some VWM lesions, indicating an active ongoing demyelinating process. In the normal appearing white matter, the number of oligodendrocytes is significantly increased [15, 74]. A substantial number of oligodendrocytes display the morphological characteristics of apoptosis and express apoptosis-related proteins indicating that oligodendroglial cell loss is an early feature in the disease process $[15,88]$.

\section{Adrenoleukodystrophy}

X-linked adrenoleukodystrophy is characterized by adrenal insufficiency and CNS abnormalities. The disease is caused by mutations in the $A B C D 1$ gene leading to the accumulation of very long chain fatty acids (VLCFA) [58]. In the majority of patients, the disease starts in the first or third/ fourth decade; only in a subset of patients is the brain affected (cerebral variant of ALD) [57]. Measurement of VLCFA in plasma is the key diagnostic technique and mutation analysis will confirm the suspected diagnosis. Biopsies are needed only in exceptional situations, e.g. in patients in whom the diagnosis is unexpected due to an atypical clinical course. Histologically, cerebral ALD shares many features with MS lesions. Like MS lesions, they are characterized by demyelination, relative loss of axons and inflammation (Fig. 2f). Within the lesions, a diffuse loss of myelin proteins (MBP, CNP, MOG, MAG, PLP) is observed (Fig. 2g) and no sharp border between the lesions and the "normal appearing" white matter can be defined, similar to pattern III MS lesions. The number of oligodendrocytes is reduced within the lesion compared to the NAWM, but we observed only a few oligodendrocytes with an apoptotic or pycnotic morphology, similar to observations described by Ito et al. [36]. The number of axons is reduced and axonal spheroids can be observed. The 
perivascular and parenchymal infiltrates are composed of CD3- and CD8-positive T cells, plasma cells as well as macrophages, which may contain myelin degradation products within their cytoplasm. We did not see a deposition of complement in macrophages or on myelin, but this has been reported for a subset of patients in an earlier study [72]. Reactive and bizarrely formed astrocytes are scattered through the lesion (Fig. 2f). They are characterized by large, plump cell bodies resembling large gemistocytes. The detection of needle-like inclusions within macrophages is typical for ALD (insert in Fig. 2g). These inclusions can most readily be detected in the Luxol-Fast-Blue/PAS staining where they appear as small, colourless cavities.

\section{Alexander's disease}

Alexander's disease is caused by mutations in the GFAP gene [51] and was first described by WS Alexander [6] in 1949 and named after him in 1964 by Friede [25], who described six additional cases. An infantile, juvenile and adult variant can be distinguished. The infantile and juvenile type are often characterized by megalencephaly, hydrocephalus, seizures and developmental delay. Patients with an adult onset may show symptoms similar to those of MS patients [40]. MRI characteristics, such as extensive white matter changes with frontal predominance, a periventricular rim on $\mathrm{T} 1$, abnormalities in basal ganglia and brain stem and contrast enhancement of particular grey and white matter structures allow the diagnosis of Alexander's disease in about $90 \%$ of patients [87]. The need for a biopsy is limited to unusual disease courses or MRI characteristics such as focal lesions, where the diagnosis of Alexander's disease is unexpected. Histologically, the most prominent feature in patients with Alexander's disease is the presence of numerous Rosenthal fibres, which often accumulate perivascularly (Fig. 2i). Although Rosenthal fibres can also be found in MS lesions, they are confined to old chronic lesions in patients with long-standing disease $[61,77]$. Due to the extensive loss or pallor of myelin, the disease is regarded as a leukodystrophy (Fig. 2h). In children with classical Alexander's disease, widespread destruction of myelin, sometimes to the extent of cavitation, can be observed. In contrast, in adults only a patchy pallor of myelin may be observed. Oligodendrocytes are absent or significantly reduced in the most severely affected lesion areas and dying oligodendrocytes with condensed or fragmented nuclei can be observed. The axonal degeneration is mild compared to the extensive loss of myelin. The demyelinated areas are infiltrated by numerous foamy macrophages, while only few lymphocytes are observed. T cells are mostly found perivascularly and most of the $\mathrm{T}$ cells are CD8 positive. In addition, a few $\mathrm{B}$ cells and plasma cells are seen in the perivascular infiltrates.

\section{Viral infections associated with demyelination}

Progressive multifocal leukoencephalopathy

Progressive multifocal leukoencephalopathy (PML) was first described in 1958 by Aström, Mancall and Richardson [8]. PML is caused by an infection of oligodendrocytes by the JC virus and it affects patients who suffer from diseases compromising the immune system, such as tuberculosis, leukaemia and AIDS [23, 67, 93].

Histopathologically, PML is characterized by demyelinated lesions of different sizes, which may show necrotic areas at the centre of the lesion [46]. The lesions are located in all parts of the brain (hemisphere, brainstem, cerebellum). The borders of the lesions may be ill defined or clearly defined (Fig. 3a). The neuropathological hallmarks are bizarre giant astrocytes (Fig. 3a) and oligodendrocytes infected by JC virus showing enlarged hyperchromatic nuclei (Fig. 3b). The demyelinated areas are infiltrated by numerous foamy macrophages. Perivascular infiltrates consisting of $\mathrm{T}$ cells, macrophages and a few $\mathrm{B}$ cells may be observed, especially in AIDS-associated PML [46]. JC virus infection as the cause of demyelination can be proven by the detection of JC virus in oligodendrocytes and (more rarely) astrocytes; infected cells are more frequently found at the lesion border than in the demyelinated lesion centre.

\section{Subacute sclerosing panencephalitis}

Subacute sclerosing panencephalitis (SSPE) is caused by a persistent measles virus infection. The onset of the disease, that affects mostly children, is insidious, and the outcome often fatal. With the introduction of measles vaccination, the incidence of SSPE has significantly decreased.

First, pathologic changes are observed in the white matter of the hemisphere [63]. The histopathological changes are relatively unspecific: widespread, but focal perivascular infiltrates in the white and grey matter associated with astrocytic proliferation as well as microglial nodules. These inflammatory reactions are accompanied by diffuse demyelination (Fig. 3c), which can be very limited in early disease stages. In neuronal or oligodendroglial nuclei, specific inclusions may be found, the so-called Cowdry type A inclusion bodies. The detection of measles virus antigen by immunohistochemistry leads to the definitive diagnosis of SSPE (Fig. 3d, e) [20].

\section{Encephalitis without demyelination}

Encephalitis may present with multifocal lesions in the grey and white matter and is therefore the basis for a possible diagnosis of multiple sclerosis in certain circumstances. Encephalitis without demyelination is most 
Fig. 3 PML, SSPE and viral encephalitis. PML lesions may be characterized by a sharp lesion border [LFB-PAS; (a)]. The histopathological hallmarks are bizarre astrocytes (immunohistochemistry for GFAP; insert in a) and viral inclusion bodies in oligodendrocytes and astrocytes [immunohistochemistry with antibodies recognizing JC antigens; (b)]. SSPE is characterized by demyelinated lesions often accompanied by extensive axonal loss [immunohistochemistry for MAG; (c)]. In oligodendroglial nuclei, viral inclusions can be found, which are intensively eosinophilic [haematoxylin and eosin; (d)]. Measles virus antigen can be identified by immunohistochemistry (e). In acute viral encephalitis, e.g. in acute measles encephalitis, marked perivascular infiltrates are observed while the myelin is not affected [LFB-PAS staining; (f)]. In this patient, measles virus antigen could be detected in oligodendroglial nuclei (insert in $f$ ). The perivascular infiltrates may be dominated by $\mathrm{B}$ cells [immunohistochemistry for the B cell marker CD20; (g)]
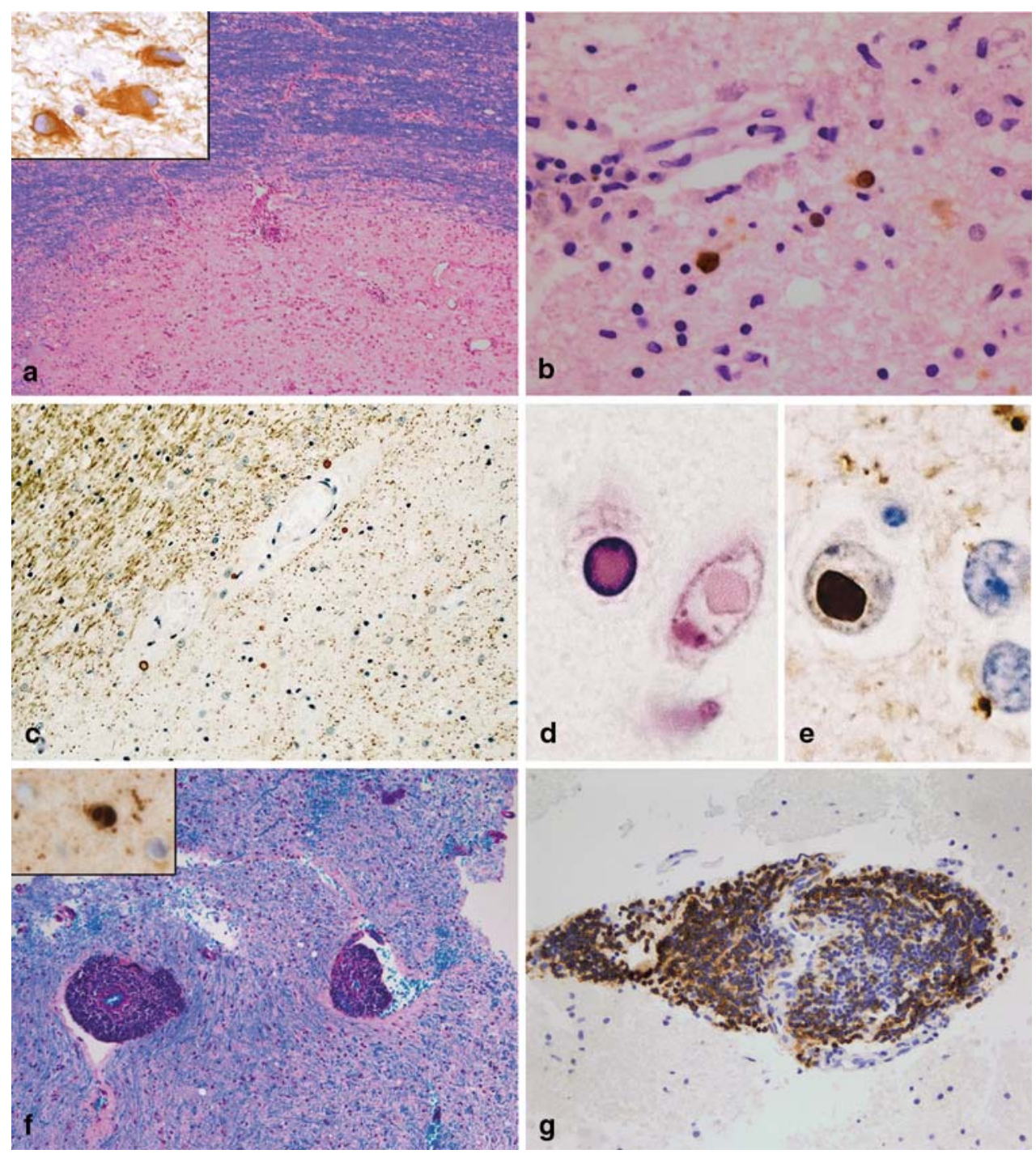

frequently caused by infectious pathogens or an autoimmune process.

Among the infectious pathogens, viral infections are the most important cause of encephalitis without demyelination. Necrotizing viral encephalitis, such as herpes, CMV or VZV, is easy to diagnose; the detection of the virus by immunohistochemistry permits the definitive diagnosis. Unfortunately, there are numerous additional viruses, which may cause encephalitis, but are more difficult to identify. Arboviruses (West Nile virus, Japanese encephalitis, St Louis encephalitis, Western and Eastern equine encephalitis, Central European tick-born encephalitis) and enteroviruses (echovirus, coxsackievirus) are some known examples that infect the CNS and result in encephalitis and/ or meningitis. Viral encephalitis affects predominately the cortex. The histological characteristics consist of perivascular and parenchymal infiltrates (lymphocytes, macrophages, microglia; Fig. 3g), microglial nodules as well as dying nerve cells surrounded by microglial cells (neuronophagia; Fig. 3f). Neurons and granzyme B expressing CD8-positive $\mathrm{T}$ can be found in close proximity, suggesting a direct cytotoxic effect of CD8 T cells on neurons.

Autoimmune processes are a further cause for encephalitis without demyelination. In a subset of patients, autoimmunemediated encephalitis is associated with malignancies (also called paraneoplastic encephalopathy or paraneoplastic encephalitis). Limbic encephalitis is the most frequent autoimmune encephalitis with 120 cases described in the literature (for review see [89]. Clinically, it is characterized by short-term memory impairment, temporal lobe seizures and psychiatric symptoms. The typical MRI findings consist of signal abnormalities in the mesial temporal lobes without contrast enhancement [10, 89]. In CSF and/or serum, autoantibodies to neuronal antigens (e.g. Voltage-gated potassium channels or intraneuronal antigens (such as anti-Hu, anti-Ma2)) [10] can be detected 
in the majority of patients. However, the pathogenesis of autoimmune encephalitis is still a matter of debate; autoantibody-mediated neuronal cell lysis as well as cellular immune mechanisms are discussed $[3,4,70]$. The histological CNS changes in patients with autoimmune encephalitis consist of perivascular $\mathrm{T}$ and $\mathrm{B}$ cell infiltrates, microglial activation, microglial nodules and gliosis $[19,90]$. Rasmussen encephalitis is another rare syndrome in which an autoimmune reaction is the suspected underlying cause of the disease. It affects predominately children, but it can in rare instances also be seen in adults. It is characterized by a progressive destruction of one hemisphere. In early disease phases, the pathological changes consisting of focal and/or perivascular inflammatory infiltrates (with a prominent number of $\mathrm{CD} 8$ positive $\mathrm{T}$ cells), microglia activation, astrocytosis and single neuronophagia are limited to the superficial and deep cortical layers. Cytotoxic T cells are seen in close association with cortical neurons, suggesting a $\mathrm{T}$ cell-mediated mechanism of tissue injury [13]. In addition, profound loss and acute destruction of astrocytes is a characteristic feature of active lesions. In contrast, in late disease phases, extensive destruction with vacuolation of all cortical layers, massive loss of neurons and a prominent astrocytosis were found, while the lymphocytic infiltration was minimal or absent [13]. The subcortical white matter may be affected as well, displaying a diffuse pallor of myelin, loss of axons, foci of lymphocytic infiltrates and reactive astrocytic changes [11, 69].

\section{Vasculitis}

CNS vasculitis is a heterogeneous disease group, which represents either isolated vasculitis of the CNS or is part of a systemic vasculitis, such as Wegner's granulomatosis, Churg-Strauss syndrome, polyarteritis nodosa or collagenoses associated with vasculitis (for review, see [37, 92].

CNS vasculitis mostly affects small- and medium-sized vessels. The histological hallmarks of CNS vasculitis are infiltration of the vessel wall with inflammatory cells (Fig. 4a) and a fibrinoid necrosis of the vessel wall. The inflammatory destruction of the vessels (Fig. 4b) results in thrombosis of the vessels causing strokes or haemorrhages. The inflammation within the vessel wall consists of macrophages, $\mathrm{T}$ cells and $\mathrm{B}$ cells, and occasionally giant cells are
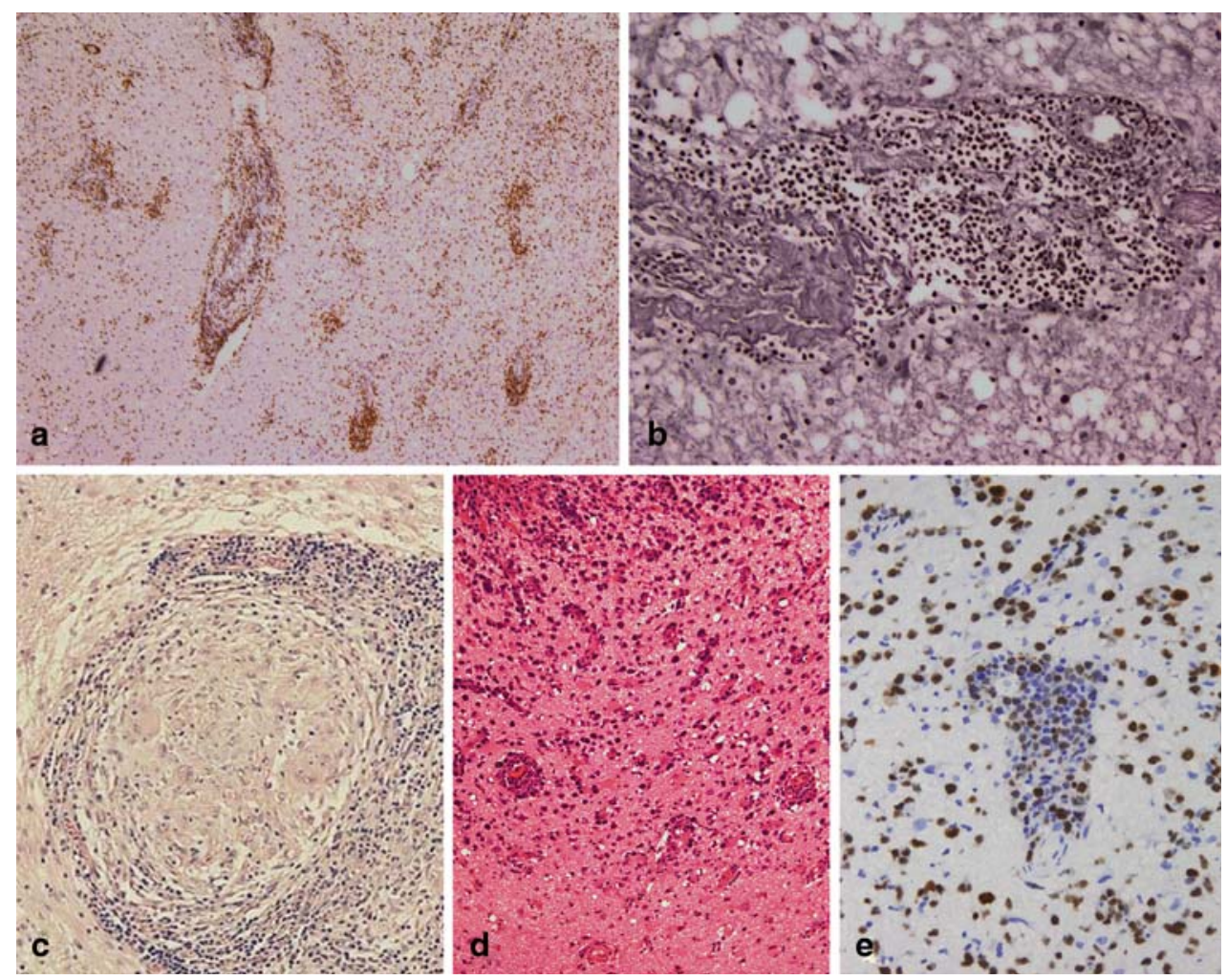

Fig. 4 In vasculitis, the infiltrates are localized within the vessel wall and consist mostly of $\mathrm{T}$ cells [immunohistochemistry for the $\mathrm{T}$ cell marker CD3; (a)]. Frequently, the vessel wall is destroyed [reticulin staining; (b)]. Noncaseating granulomas consisting of multinucleated giant cells and epitheloid cells surrounded by a lymphocytic wall are the histological hallmarks of neurosarcoidosis (c). In CNS lymphomas, a perivascular accumulation of neoplastic B cells is characteristic [haematoxylin and eosin; (d)]. The high proliferation index in lymphomas may help to distinguish lymphomas from vasculitis or viral encephalitis. However, occasionally also cases of vasculitis and encephalitis show a marked proliferation. The detection of a monoclonal B cell population by PCR confirms the suspected diagnosis of a B cell lymphoma [immunohistochemistry for the proliferation marker Ki67; (e)] 
found as well. The vasculitis may be accompanied by mild to severe inflammatory infiltrates in the CNS parenchyma making the differentiation between MS and vasculitis occasionally difficult in the absence of a fibrinoid necrosis of the vessel walls or thrombotic vessels. In contrast to MS, no demyelination is observed.

\section{Sarcoidosis}

Sarcoidosis is a chronic relapsing inflammatory disease of unknown aetiology with variable clinical manifestations; the most common presentation of sarcoidosis is pulmonary involvement. The CNS is affected in 5-25\% of the patients $[39,55,81]$. Cranial MRI reveals the predilection of neurosarcoidosis for the leptomeninges and basal midline structures such as hypothalamus, optic chiasm and the pituitary gland, but also multiple hyperintense parenchymal and periventricular lesions are observed, which may be indistinguishable from MS lesions [56, 65, 83]. In the absence of a systemic disease, pathological evaluation of one of the CNS lesions is the only way to establish the diagnosis of neurosarcoidosis.

Histopathologically, neurosarcoidosis is characterized by non-caseating granulomas consisting of epitheloid histiocytes, lymphocytes, plasma cells and multinucleated giant cells (Fig. 4c). The nuclei in the giant cells are either arranged along the cell border or are randomly clustered in the cytoplasm. In rare instances, necrotizing granulomas can be found in patients with neurosarcoidosis [65]. ZiehlNeelsen and auramine-rhodamine stainings (mycobactria), silver impregnation techniques (fungi) and examination with polarized light help to distinguish neurosarcoidosis from other granulomatous diseases such as tuberculosis, fungal infections (e.g. histoplasmosis, aspergillosis, cryptococcosis) or foreign body type granulomatous inflammation.

\section{Hypoxic-ischaemic demyelination and necrosis}

Multifocal ischaemic lesions may mimic the radiological findings of MS, especially in the early stages [68]. Histopathologically, hypoxia or ischaemia results in necrosis rather than demyelination. In contrast to demyelination, necrotic processes are characterized by loss of axons and myelin. Stainings, which identify myelin and axons will help to distinguish between necrotic and demyelinating diseases. Early stages of strokes, which show a diffuse myelin pallor and preserved axons also display marked neuronal cell death in the affected cortex areas and/or an invasion of granulocytes; neither finding is observed in MS lesions. Binswanger's disease is characterized by diffuse perivascular demyelination. The atherosclerotic vessel changes and the absence of a marked inflammatory reaction lead to the unequivocal diagnosis of Binswanger's disease.

\section{Tumours}

\section{Sentinel lesions}

Malignant lymphoma, which accounts for less than $1 \%$ of all brain tumours, may be associated with or even preceded by demyelinating lesions. The underlying mechanism for developing sentinel lesions is unknown. A viral pathogenesis, malignant transformation of a chronic inflammatory process or demyelination due to anti-myelin antibodies secreted by the lymphoma cells are discussed [32]. The sentinel lesions show typical histological features of MS lesions, such as demyelination, extensive macrophage infiltration, lymphocytic infiltrates consisting of $\mathrm{T}$ cells (CD3 and CD8), B cells and plasma cells and a relative preservation of axons. These lesions are indistinguishable from MS lesions by histology $[5,14,47,48]$. The diagnosis of sentinel lesions should be considered if patients with untypical age of onset of MS ( $>60$ years) present with monofocal demyelinating lesions. MR spectroscopy may help to distinguish between demyelinating disease and lymphoma [47]. For pathology, complete serial sections of the respective biopsy may help to arrive at a definite diagnosis, since in such cases small perivascular angiocentric accumulations of neoplastic T or B cells can be found.

\section{Lymphoma}

Primary B cell lymphomas of the CNS (PCNSL) are relatively rare; they account for less than $1 \%$ of CNS tumours. Although lymphomas and MS lesions may cause similar MRI changes [52, 66], these two entities can be distinguished easily by histology. B cell lymphomas are easy to diagnose due to their high cellularity, angiocentric growth pattern (Fig. 4d), typical morphology, high proliferation (Fig. 4e), and immunopositivity for B cell markers. However, treatment of patients with steroids prior to biopsy may obscure the diagnosis of lymphoma. Treatment with steroids may lead to the almost complete elimination of the neoplastic B cell population resulting in astrogliosis and perivascular $\mathrm{T}$ cell infiltrates resembling vasculitis or encephalitic diseases [28]. Occasionally, B cell lymphomas are preceded by demyelinating lesions, undistinguishable from MS lesions, as described in detail above [5, 14, 47, 48].

A rare variant of PCNSL is the lymphomatosis cerebri that in contrast to the typical PCNSL does not form a cohesive mass, but infiltrates into the CNS diffusely and widely $[9,75]$. The patients typically present with rapidly progressive dementia. As a result of the diffuse infiltration of lymphomatosis cerebri, MRI findings may mimic other white matter disorders, such as Binswanger disease, leukoencephalopathy, viral infection or infiltrating glioma [21, 26, 82]. 
Histopathologically, lymphomatosis cerebri is characterized by the infiltration of the white matter with individual CD20-positive lymphoid lymphoma cells without forming mass lesions [9, 42, 75]. Modest numbers of lymphoma cells together with reactive $T$ cells can be found perivascularly. These histopathological changes may be associated with subtle myelin pallor. One case report describes the presence of focal necrosis [9].

It may be especially challenging to differentiate $\mathrm{T}$ cell lymphomas of the CNS from inflammatory entities, such as vasculitis. In a large series of PCNSL $(n=370)$, T cell origin has been described in $2 \%$ of the cases [24]. Primary T cell lymphomas of the CNS frequently show an angiocentric growth pattern. The morphology of the neoplastic $\mathrm{T}$ cells has been described as small, medium to large or pleomorphic [33, 79]. Parenchymal necroses as well as necrotic vessels may be present. Immunohistochemically, the neoplastic cells express CD3 as well as CD8 and perforin or granzyme B [33]. Proliferation is usually prominent. The detection of a clonal $\mathrm{T}$ cell receptor gene rearrangement by PCR helps to establish the diagnosis of a T cell lymphoma [33].

\section{Other CNS tumours}

Since early MS lesions are characterized by hypercellularity as well as extensive and prominent astrocytosis, they might be confused with astrocytic tumours, especially in small biopsy specimens. Furthermore, reactive astrocytes in MS lesions often display a marked pleomorphism and even astrocytes, with atypical mitotic figures (Creutzfeldt-Peters cells) being observed in MS lesions. Therefore, low-grade astrocytomas, especially those with a prominent gemistocytic component may lead to confusion in the differential diagnosis of demyelinating lesions.

The hypercellularity observed in early MS lesions is at least partly caused by macrophages. Cytologically, macrophages may resemble neoplastic oligodendrocytes. However, while neoplastic oligodendrocytes often have a clear cytoplasm as an artificial reaction to the embedding process, macrophages display a foamy and granular cytoplasm. The presence of demyelination and relative axonal preservation together with stainings identifying macrophages (e.g. CD68, KiM1P) will help to avoid misdiagnosis. Review of the clinical and radiological findings will further help towards a correct diagnosis.

\section{Practical guidelines for diagnosing MS}

We recommend starting the diagnostic process with three basic stainings: HE, LFB-PAS myelin staining and a staining for the detection of axons (e.g. Bielschowsky's silver impregnation). These three stainings are sufficient to deter- mine the extent of inflammation, the localization of inflammatory infiltrates (perivascular versus diffuse in the parenchyma), the extent of demyelination (LFB-PAS) and the severity of axonal damage. Additional immunohistological stainings for macrophages, $\mathrm{T}$ cells, B cells, plasma cells, astrocytes and proliferation are sufficient to narrow down the differential diagnosis as described in Fig. 5. Having an additional myelin marker at hand might be helpful, especially because immunohistochemistry for myelin proteins is less time consuming than conventional myelin stainings, such as LFB. We recommend as immunohistochemical myelin markers anti-MBP or anti-CNP, which both reliably label myelin sheaths and, in the case of the latter one, also oligodendrocytes.

An important first step in the diagnostic process is to exclude a neoplasm. Stainings for myelin, axons and macrophages will help in distinguishing between MS and a glial tumour. Limited demyelination together with dense (peri-) vascular accumulation of $\mathrm{T}$ and/or $\mathrm{B}$ cells characterizes lymphomas and vascultits. Additional immunohistochemical stainings for identification of B cells (CD20, CD79a) and proliferation (Ki67) make it possible to differentiate between lymphoma and MS. The detection of a monoclonal $\mathrm{B}$ cell population by PCR leads to the unequivocal diagnosis of a B cell lymphoma of the CNS. Extensive demyelination is found in MS, sentinel lesions, PML and rare demyelinating diseases such as Alexander's disease or leukodystrophies. Alexander's disease and leukodystrophies can be easily distinguished from multiple sclerosis lesions by the presence of numerous Rosenthal fibres in the former and phagocytic inclusions in the latter. PML is characterized by bizarre astrocytes, and the suspected diagnosis can be proved if JC virus is detected within the oligodendrocytes and/or astrocytes. Other demyelinating diseases such as CPM and vanishing white matter show a very limited number of T and B cells in contrast to MS lesions. By combining a myelin staining with an axonal staining, a demyelinating process can be distinguished from a necrotic one. Necrosis is a very rare finding in MS lesions; except for fulminant MS disease courses, it is rarely observed in MS. When present, a differential diagnosis of NMO should be considered. The presence of necrosis strongly favours the diagnosis of either a necrotic encephalitis or an ischaemic lesion.

Once the diagnosis of an inflammatory demyelinating process is established, further stainings for different myelin proteins, apoptotic cells and the composition of the inflammatory reaction makes it possible to further distinguish one of the different MS patterns as described above [53]. This subclassification can only be performed in actively demyelinating lesions characterized by the presence of myelin degradation products, such as MOG, MAG or CNP within the cytoplasm of macrophages. Since the histological MS 
Fig. 5 Flow chart for the diagnosis of MS and its most important differential diagnosis. ADEM acute disseminated encephalomyelitis, $C P M$ central pontine myelinolysis, $A H L$ acute haemorrhagic necrotizing leukoencephalitis; $M B D$ Marchiafava-Bignami disease, $M S$ multiple sclerosis, $P M L$ progressive multifocal leukoencephalopathy, RTF Rosenthal fibres, $S S P E$ subacute sclerosing panencephalitis, $V W M$ vanishing white matter disease

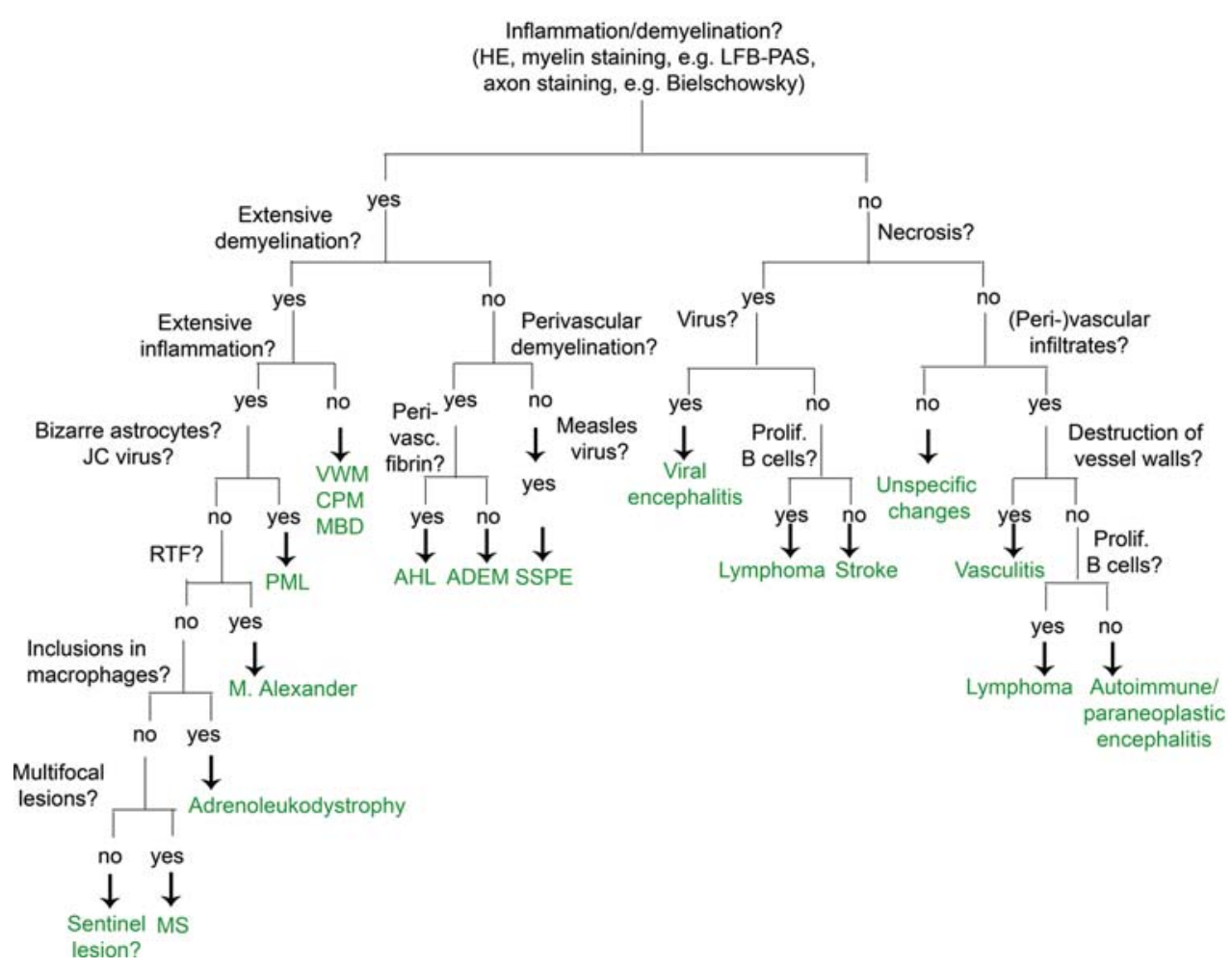

pattern may influence the treatment strategies [43], we recommend sending the MS biopsies to specialized centres for further classification.

Acknowledgements This study was supported by the research program from the Faculty of Medicine, Georg-August-University Göttingen, the Hertie Foundation and 6th Framework of the European Union, NeuroproMiSe, LSHM-CT-2005-018637. We thank our colleagues from the Departments of Neuropathology from Bremen, Erlangen/ Nürnberg, Ulm, Mainz, Greifswald, Department of Pathology and Dermatopathology, Diagnostic Centre, Berlin, the Montreal Neurological Institute, Montreal, Canada as well as our colleagues from the Department of Neurology from the University of Lodz, Poland for providing tissue specimens.

Open Access This article is distributed under the terms of the Creative Commons Attribution Noncommercial License which permits any noncommercial use, distribution, and reproduction in any medium, provided the original author(s) and source are credited.

\section{References}

1. Adams RD, Kubik CS (1952) The morbid anatomy of demyelinative diseases. Am J Med 12:510-546

2. Adams RD, Victor M, Mancall EL (1959) Central pontine myelinolysis. A hitherto undescribed disease occurring in alcoholic and malnourished patients. Arch Neurol Psych 8138:154-172

3. Albert M, Austin L, Darnell R (2000) Detection and treatment of activated $\mathrm{T}$ cells in the cerebrospinal fluid of patients with paraneoplastic cerebellar degeneration. Ann Neurol 47:9-17

4. Albert M, Darnell J, Bender A, Francisco L, Bhardwaj N, Darnell R (1998) Tumor-specific killer cells in paraneoplastic cerebellar degeneration. Nat Med 4:1321-1324
5. Alderson L, Fetell MR, Sisti M, Hochberg F, Cohen M, Louis DN (1996) Sentinel lesions of primary CNS lymphoma. J Neurol Neurosurg Psychiatry 60:102-105

6. Alexander W (1949) Progressive fibrionoid degeneration of fibrillary astrocytes associated with mental retardation in a hydrocephalic infant. Brain 72:373-381

7. Anderson D, Ellenberg J, Leventhal C, Reingold S, Rodriguez M, Silberberg D (1992) Revised estimate of the prevalence of multiple sclerosis in the United States. Ann Neurol 31:333-336

8. Aström K, Mancall E, Richardson E (1958) Progressive multifocal leukoencephalopathy. Brain 81:93-111

9. Bakshi R, Mazziotta J, Mischel P, Jahan R, Seligson D, Vinters H (1999) Lymphomatosis cerebri presenting as a rapidly progressive dementia: clinical, neuroimaging and pathologic findings. Dement Geriatr Cogn Disord 10:152-157

10. Bataller L, Kleopa K, Wu G, Rossi J, Rosenfeld M, Dalmau J (2007) Autoimmune limbic encephalitis in 39 patients: immunophenotypes and outcome. J Neurol Neurosurg Psychiatry 78:381-385

11. Bauer J, Elger CE, Hans VHH, Schramm J, Urbach H, Lassmann H, Bien CG (2007) Astrocytes are a specific immunological target in Rasmussen's encephalitis. Ann Neurol 62:67-80

12. Biancheri R, Rossi A, Di Rocco M, Filocamo M, Pronck J, van der Knaap M, Tortori-Donati P (2003) Leukoencephalopathy with vanishing white matter: an adult onset case. Neurology 61:18181819

13. Bien CG, Bauer J, Deckwerth TL, Wiendl H, Deckert M, Wiestler OD, Schramm J, Elger CE, Lassmann H (2002) Destruction of neurons by cytotoxic $\mathrm{T}$ cells: a new pathogenic mechanism in Rasmussen's encephalitis. Ann Neurol 51:311-318

14. Brecher K, Hochberg FH, Louis DN, de la Monte S, Riskind P (1998) Case report of unusual leukoencephalopathy preceding primary CNS lymphoma. J Neurol Neurosurg Psychiatry 65:917-920

15. Brück W, Herms J, Brockmann K, Schulz-Schaeffer W, Hanefeld F (2001) Myelinopathia centralis diffusa (vanishing white matter disease): evidence of apoptotic oligodendrocyte degeneration in early lesion development. Ann Neurol 50:532-536 
16. Bruck W, Kuhlmann T, Stadelmann C (2003) Remyelination in multiple sclerosis. J Neurol Sci 206:181-185

17. Brück W, Neubert K, Berger T, Weber JR (2001) Clinical, radiological, immunological and pathological findings in inflammatory CNS demyelination: possible markers for an antibody-mediated process. Mult Scler 7:173-177

18. Brück W, Sommermeier N, Bergmann M, Zettl U, Goebel HH, Kretzschmar HA, Lassmann H (1996) Macrophages in multiple sclerosis. Immunobiology 195:588-600

19. Buckley C, Oger J, Clover L, Tüzün E, Carpenter K, Jackson M, Vincent A (2001) Potassium channel antibodies in two patients with reversible limbic encephalitis. Ann Neurol 50:73-78

20. Budka H, Lassmann H, Popow-Kraupp T (1982) Measles virus antigen in panencephalitis. An immunomorphological study stressing dendritic involvement in SSPE. Acta Neuropathol 56:52-62

21. Carlson BA (1996) Rapidly progressive dementia caused by nonenhancing primary lymphoma of the central nervous system. AJNR Am J Neuroradiol 17:1695-1697

22. Dale RC, de Sousa C, Chong WK, Cox TCS, Harding B, Neville BGR (2000) Acute disseminated encephalomyelitis, multiphasic disseminated encephalomyelitis and multiple sclerosis in children. Brain 123:2407-2422

23. Dörries K, ter Meulen V (1983) Progressive multifocal leukencephalopathy: detection of papovavirus JC in kidney tissue. J Med Virol 11:307-317

24. Ferreri AJ, Reni M, Pasini F, Calderoni A, Tirelli U, Pivnik A, Aondio GM, Ferrarese F, Gomez H, Ponzoni M, Borisch B, Berger F, Chassagne C, Iuzzolino P, Carbone A, Weis J, Pedrinis E, Motta T, Jouvet A, Barbui T, Cavalli F, Blay JY (2002) A multicenter study of treatment of primary CNS lymphoma. Neurology 58:1513-1520

25. Friede R (1964) Alexander's disease. Arch Neurol 11:414-422

26. Furusawa T, Okamoto K, Ito J, Kojima N, Oyanagi K, Tokiguchi S, Sakai K (1998) Primary central nervous system lymphoma presenting as diffuse cerebral infiltration. Radiat Med 16:137-140

27. Gallo A, Rocca MA, Falini A, Scaglipone C, Gambini A, Guerrini L, Mascalchi M, Pronk J, van der Knaap M, Fillipi M (2004) Multiparametric MRI in a patient with adult-onset leukoencephalopathy with vanishing white matter. Neurology 62:323-326

28. Geppert M, Ostertag CB, Seitz G, Kiessling M (1990) Glucocorticoid therapy obscures the diagnosis of cerebral lymphoma. Acta Neuropathol 80:629-634

29. Ghatak N, Hadfield M, Rosenblum W (1978) Association of central pontine myelinolysis and Marchiafava-Bignami disease. Neurology 28:1295-1298

30. Ghosh N, DeLuca GC, Esiri MM (2004) Evidence of axonal damage in human acute demyelinating diseases. J Neurol Sci 222:29-34

31. Gocht A, Colmant HJ (1987) Central pontine and extrapontine myelinolysis: a report of 58 cases. Clin Neuropathol 6:262-270

32. Hanto DW, Frizzera G, Gajl-Peczalska KJ, Sakamoto K, Purtilo DT, Balfour HH Jr, Simmons RL, Najarian JS (1982) Epstein-Barr virus-induced B-cell lymphoma after renal transplantation. N Engl J Med 306:913-918

33. Harder A, Dudel C, Anagnostopoulos I, Hummel M, Bruck W (2003) Molecular genetic diagnosis of a primary central nervous system T cell lymphoma. Acta Neuropathol (Berl) 105:65-68

34. Hart MN, Earle KM (1975) Haemorrhagic and perivenous encephalitis: a clinico-pathological review of 38 cases. J Neurol Neurosurg Psychiatry 38:585-591

35. Hynson JL, Kornberg AJ, Coleman LT, Shield L, Harvey AS, Kean MJ (2001) Clinical and neuroradiologic features of acute disseminated encephalomyelitis in children. Neurology 56:1308-1312

36. Ito M, Blumberg BM, Mock DJ, Goodman A, Moser AB, Smith KD, Powers J (2001) Potential environmental and host participants in the early white matter lesion of adreno-leukodystrophy: morphologic evidence for CD8 cytotoxic T cells, cytolysis of oligo- dendrocytes, and CD1.mediated lipid antigen. J Neuropathol Exp Neurol 60:1004-1019

37. Jennette J, Falk R (2007) Nosology of primary vasculitis. Curr Opin Rheumatol 19:10-16

38. Johkura K, Naito M, Naka T (2005) Cortical involvement in Marchiafava-Bignami disease. AJNR Am J Neuroradiol 26:670-673

39. Johns C, Michele T (1999) The clinical management of sarcoidosis: a 50-year experience at the Johns Hopkins Hospital. Medicine 78:65-111

40. Johnson A, Brenner M (2003) Alexander's disease: clinical, pathologic, and genetic features. J Child Neurol 18:625-632

41. Jorens P, VanderBorght A, Ceulemans B, Van Bever H, Bossaert L, Teven M, Goossens H, Parizel P, Van Dijk H, Raus J, Stinissen P (2000) Encephalomyelitis-associated antimyelin autoreactivity induced by streptococcal exotoxins. Neurology 54:1433-1441

42. Kanai R, Shibuya M, Hata T, Hori M, Hirabayashi K, Terada T, Fujii K (2007) A case of 'lymphomatosis cerebri' diagnosed in an early phase and treated by whole brain radiation: case report and literature review. J Neurooncol DOI:101007/s11060-007-943-9

43. Keegan M, Konig F, McClelland R, Bruck W, Morales Y, Bitsch A, Panitch H, Lassmann H, Weinshenker B, Rodriguez M, Parisi J, Lucchinetti C (2005) Relation between humoral pathological changes in multiple sclerosis and response to therapeutic plasma exchange. Lancet 366:579-582

44. Kleinschmidt-DeMasters BK, Norenberg MD (1981) Rapid correction of hyponatremia causes demyelination: relation to central pontine myelinolysis. Science 211:1068-1070

45. Kleinschmidt-DeMasters BK, Norenberg MD (1982) Neuropathologic observations in electrolyte-induced myelinolysis in the rat. J Neuropathol Exp Neurol 41:67-80

46. Kuchelmeister K, Gullotta F, Bergmann M, Angeli G, Masini T (1993) Progressive multiofocal leukoencephalopathy (PML) in the acquired immunodeficiency syndrome (AIDS). Path Res Pract 189:163-173

47. Kuhlmann T, Schröter A, Dechent P, Weber F, Rustenbeck HH, Füzesi L, Brück W, Ehrenreich H, Frahm J (2001) Diagnosis of multifocal B cell lymphoma with preceding demyelinating CNS lesions by single-voxel proton MR spectroscopy. J Neurol Neurosurg Psychiatry 70:259-262

48. Kuroda Y, Kawasaki T, Haraoka S, Fujiyama F, Kakigi R, Abe M, Tabuchi K, Kuroiwa T, Kishikawa T, Sugihara H (1992) Autopsy report of primary CNS B-cell lmphoma indistinguishable from multiple sclerosis: diagnosis with the immunoglobulin gene rearrangements analysis. J Neurol Sci 111:173-179

49. Leegwater PAJ, Vermeulen G, Könst AAM, Naidu S, Mulders J, Visser A, Kersbergen P, Mobach D, Fonds D, van Berkel CGM, Lemmers RJLF, Frants RR, Oudejans CBM, Schutgens RBH, Pronk JC, van der Knaap MS (2001) Subunits of the translation initiation factor eIF2B are mutant in leukoencephalopathy with vanishing white matter. Nature Genet 29:383-388

50. Lennon VA, Wingerchuk DM, Kryzer TJ, Pittock SJ, Lucchinetti CF, Fujihara K, Nakashima I, Weinshenker BG (2004) A serum autoantibody marker of neuromyelitis optica: distinction from multiple sclerosis. Lancet 364:2106-2112

51. Li R, Johnson A, Salomons G, Goldman J, Naidu S, Quinlan R, Cree B, Ruyle S, Banwell B, D'Hooghe M, Siebert J, Rolf C, Cox H, Reddy A, Gutiérrez-Solana L, Collins A, Weller R, Messing A, van der Knaap M, Brenner M (2005) Glial fibrillary acid protein mutations in infantile, juvenile, and adult forms of Alexander disease. Ann Neurol 57:310-326

52. Liew C, Shyu W, Tsao W, Li H (2006) Intravascular lymphomatosis mimics a cerbral demyelinating disorder. Acta Neurol Taiwan 15:264-268

53. Lucchinetti C, Brück W, Parisi J, Scheithauer B, Rodriguez M, Lassmann H (2000) Heterogeneity of multiple sclerosis lesions: implications for the pathogenesis of demyelination. Ann Neurol 47:707-717 
54. Lucchinetti CF, Mandler RN, McGavern D, Brück W, Gleich G, Ransohoff RM, Trebst C, Weinshenker B, Wingerchuk D, Parisi JE, Lassmann H (2002) A role for humoral mechanisms in the pathogenesis of Devic's neuromyelitis optica. Brain 125:1450-1461

55. Lury K, Smith J, Matheus M, Castillo M (2004) Neurosarcoidosis-review of imaging findings. Semin Roentgenol 39:495-504

56. Marangoni S, Argentiero V, Tavolato B (2006) Neurosarcoidosis. Clinical description of 7 cases with a proposal for a new diagnostic strategy. J Neurol 253:488-495

57. Moser H, Dubey P, Fatemi A (2004) Progress in X-linked adrenoleukodystrophy. Curr Opin Neurol 17:263-269

58. Mosser J, Douar A, Sarde J, Kioschis P, Feil R, Moser H, Poustka A, Mandel J, Aubourg P (1993) Putative X-linked adrenoleukodystrophy gene shares unexpected homology with $\mathrm{ABC}$ transporters. Nature 361:726-730

59. Murthy SN, Faden HS, Cohen ME, Bakshi R (2002) Acute disseminated encephalomyelitis in children. Pediatrics 110:e21

60. Newell KL, Kleinschmidt-DeMasters BK (1996) Central pontine myelinolysis at autopsy: a twelve-year retrospective analysis. J Neurol Sci 142(1-2):134-139

61. Nishie M, Mori F, Ogawa M, Sannohe S, Tanno K, Kurahashi K, Kuroda N, Wakabayashi K (2004) Multinucleated astrocytes in old demyelinated plaques in a patient with multiple sclerosis. Neuropathology 24:248-253

62. Norenberg MD, Leslie KO, Robertson AS (1982) Association between rise in serum sodium and central pontine myelinolysis. Ann Neurol 11:128-135

63. Oguz K, Celebi A, Anlar B (2007) MR imaging, diffusion-weighted imaging and MR spectroscopy findings in acute rapidly progressive subacute sclerosisn panencephalitis. Brain Dev 29:306-311

64. Okeda R, Kitano M, Sawabe M, Yamada I, Yamada M (1986) Distribution of demyelinating lesions in pontine and extrapontine myelinolysis - three cases including one devoid of central pontine myelinolysis. Acta Neuropathol 69:259-266

65. Omuro A, Leite C, Mokhtari K, Delattre J-Y (2006) Pittfalls in the diagnosis of brain tumours. Lancet Neurol 5:937-948

66. Ormsby A, Prayson RA, Heard R (1999) Angiotrophic large cell lymphoma mimicking multiple sclerosis associated transverse myelitis. J Clin Neurosci 6:408-410

67. Padgett BL, ZuRhein GM, Walker DL, Eckroade RJ, Dessel BH (1971) Cultivation of Papova-like virus from human brain with progressive multifocal leukoencephalopathy. Lancet 12:1257-1260

68. Pandey T, Abubacker S (2006) Cerebral autosomal dominant arteriopathy with subcortical infarcts and leukoencephalopathy: an imaging mimic of multiple sclerosis. A report of two cases. Med Princ Pract 15:391-395

69. Pardo CA, Vining E, Guo L, Skolasky R, Carson B, Freemanm J (2004) The pathology of Rasmussen syndrome: stage of cortical involvement and neuropathological studies of 45 hemisperectomies. Epilepsia 45:516-526

70. Plonquet A, Garcia-Pons F, Fernandez E, Phillipe C, Marquet J, Rouard H, Delfau-Larue M, Kosmatopoulos K, Lemonnier F, Farcet J, Gerhardi RKL-D (2003) Peptides derived from the onconeural $\mathrm{HuD}$ protein can elicit cytotoxic responses in HHD mouse and human. J Neuroimmunol 142:93-100

71. Pohl-Koppe A, Burchett S, Thiele E, Hafler D (1998) Myelin basic protein reactive Th2 $\mathrm{T}$ cells are found in acute disseminated encephalomyelitis. J Neuroimmunol 91:19-27

72. Powers JM, Liu Y, Moser AB, Moser HW (1992) The inflammatory myelinopathy of adreno-leukodystrophy: cells, effector molecules, and pathogenetic implications. J Neuropathol Exp Neurol 51:630-643

73. Prass K, Brück W, Schröder NWJ, Bender A, Prass M, Wolf T, van der Knaap MS, Zschenderlein R (2001) Adult-onset leukoencephalopathy with vanishing white matter presenting with dementia. Ann Neurol 50:665-668
74. Rodriguez D, Gelot A, della Gaspera B, Robain O, Ponsot G, Sarliève LL, Ghandour S, Pompidou A, Dautigny A, Aubourg P, Pham-Dinh D (1999) Increased density of oligodendrocytes in childhood ataxia with diffuse central hypomyelination $(\mathrm{CACH})$ syndrome: neuropathological and biochemical study of two cases. Acta Neuropathol 97:469-480

75. Rollins K, Kleinschmidt-DeMasters B, Corboy J, Damek D, Filley C (2005) Lymphomatosis cerebri as a cause of white matter dementia. Hum Pathol 36:282-290

76. Rust R (2000) Multiple sclerosis, acute dissiminated encephalomyelitis, and related conditions. Semin Peditatr Neurol 7:66-90

77. Schlote W (1975) Piloide Astrozyten und Rosenthalsche Fasern bei Multipler Sklerose. Acta Neuropathol 33:35-44

78. Schwarz S, Mohr A, Knauth M, Wildemann B, Storch-Hagenlocher B (2001) Acute disseminated encephalomyelitis. A followup study of 40 adult patients. Neurology 56:1313-1318

79. Shenkier TN, Blay JY, O'Neill BP, Poortmans P, Thiel E, Jahnke K, Abrey LE, Neuwelt E, Tsang R, Batchelor T, Harris N, Ferreri AJ, Ponzoni M, O’Brien P, Rubenstein J, Connors JM (2005) Primary CNS lymphoma of T-cell origin: a descriptive analysis from the international primary CNS lymphoma collaborative group. J Clin Oncol 23:2233-2239

80. Sinclair C, Kirk J, Herron B, Fitzgerald U, McQuaid S (2007) Absence of aquaporin-4 expression in lesions of neuromyelitis optica but increased expression in multiple sclerosis and normal appearing white matter. Acta Neuropathol 113:187-194

81. Smith J, Matheus M, Castillo M (2004) Imaging manifestations of neurosarcoidosis. Am J Roentgenol 182:289-295

82. Terae S, Ogata A (1996) Non-enhancing primary central nervous system lymphoma. Neuroradiology 38:34-37

83. Vagal A, Shipley R, Meyer C (2007) Radiological manifestations of sarcoidosis. Clin Dermatol 25:312-325

84. van der Knaap MS, Barth PG, Gabreels FJM, Franzoni E, Begeer JH, Stroink H, Rotteveel JJ, Valk J (1997) A new leukoencephalopathy with vanishing white matter. Neurology 48:845-855

85. van der Knaap MS, Kamphorst W, Barth PG, Kraaijeveld CL, Gut E, Valk J (1998) Phenotypic variation in leukoencephalopathy with vanishing white matter. Neurology 51:540-547

86. van der Knaap MS, Leegwater PAJ, Könst AAM, Visser A, Naidu S, Oudejans CBM, Schutgens RBH, Pronk JC (2002) Mutations in each of the five subunits of translation initiation factor eIF2B can cause leukoencephalopathy with vanishing white matter. Ann Neurol 51:264-270

87. van der Knaap MS, Naidu S, Breiter N, Blaser S, Stroink H, Springer S, Begeer J, Van Coster R, Barth P, Thomas N, Valk J, Powers J (2001) Alexander disase: diagnosis with MR imaging. AJNR Am J Neuroradiol 22:541-552

88. Van Haren K, Van Der Voorn JP, Peterson DR, van der Knaap MS, Powers JM (2004) The life and death of oligodendrocytes in vanishing white matter disease. J Neuropathol Exp Neurol 63:618-630

89. Vernino S, Geschwind M, Boeve B (2007) Autoimmune encephalopathies. Neurologist 13:140-147

90. Vincent A, Buckley C, Scott J, Baker I, dewar B, Detert N, Clover L, Parkinson A, Bien C, Omer S, Lang B, Rossor M, Palace J (2004) Potassium channel antibody-associated encephalopathy: a potentially immunotherapy-responsive form of limbic encephalitis. Brain 127:701-712

91. Wong K, Armstrong RC, Gyure KA, Morrison AL, Rodriguez D, Matalon R, Johnson AB, Wollmann R, Gilbert E, Le TQ, Bradley CA, Crutchfield K, Schiffmann R (2000) Foamy cells with oligodendroglial phenotype in childhood ataxia with diffuse central nervous system hypomyelination syndrome. Acta Neuropathol 100:635-646

92. Younger D (2004) Vasculitis of the nervous system. Curr Opin Neurol 17:317-336

93. ZuRhein GM, Chou S-M (1965) Particles resembling papova viruses in human cerebral demyelinating disease. Science 148:1477-1479 